Short Communication

\title{
Preparation of new composite electrolytes for solid-state lithium rechargeable batteries by compounding LiTFSI , PVDF-HFP and LLZTO
}

\author{
Yuanchun Gu ${ }^{1, *}$, Faqian Liu ${ }^{2}$, Guangye Liu ${ }^{1}$ \\ ${ }^{1}$ Engineering Research Center of High Performance Polymer and Molding Technology, Ministry of \\ Education, Qingdao University of Science and Technology, Qingdao 266042, China. \\ ${ }^{2}$ School of Chemical Engineering and Technology, Sun Yat-sen University, Zhuhai 519082, China. \\ *E-mail: yuanchungu@163.com
}

doi: $10.20964 / 2020.12 .65$

Received: 25 August 2020 / Accepted: 9 October 2020 / Published: 31 October 2020

The addition of $\mathrm{Li}_{7} \mathrm{La}_{3} \mathrm{Zr}_{1.4} \mathrm{Ta}_{0.6} \mathrm{O}_{12}$ (LLZTO) particles to polymer electrolytes can reduce the crystallinity of polymer materials, promote the migration of lithium ions, and then improve the ionic conductivity of polymer solid electrolytes. Oxide-polymer composite solid electrolytes with different contents of LLZTO were prepared from Lithium bis(trifluoromethylsulphonyl)imide (LiTFSI), polyvinylidene fluoride-hexafluoropropylene (PVDF-HFP) and LLZTO powder as raw materials. The study has found that the solid electrolyte with $15 \mathrm{wt} \%$ LLZTO has higher ionic conductivity and mechanical strength, and has a wider electrochemical window $(5.5 \mathrm{~V})$. The prepared composite cathode electrode/solid electrolyte/composite anode electrode solid-state lithium ion battery has a chargedischarge specific capacity of $179.56 \mathrm{mAh} / \mathrm{g}$ and $146.73 \mathrm{mAh} / \mathrm{g}$ for the first cycle, the coulombic efficiency is of $84 \%$, and the discharge capacity retention rate after 30 cycles is above $94 \%$. In addition, the change of impedance before and after the cycle is small, showing good interface stability.

Keywords: Solid-state lithium battery, Composite solid electrolyte, LLZTO, LiTFSI, PVDF-HFP

\section{$\underline{\text { FULL TEXT }}$}

(C) 2020 The Authors. Published by ESG (www.electrochemsci.org). This article is an open access article distributed under the terms and conditions of the Creative Commons Attribution license (http://creativecommons.org/licenses/by/4.0/). 